by the Clinique Therapeutique of the University of Geneva.

Since so much of the chemical work associated with the identification of aldosterone, following its initial discovery by Simpson and Tait, was, in fact, carried out in Switzerland, this was an appropriate place for the symposium to be held. In the present volume there are papers on the estimation of aldosterone in urine and its isolation from the human adrenals and adrenal tumours; one on the comparison between the physiological effects of aldosterone and cortexone; studies on the metabolism of aldosterone and upon the factors regulating its secretion. There is a paper on Conn's syndrome and a brief account of the relationship of aldosterone secretion to idiopathic oedema.

This is an excellent volume and will be eagerly read by all those interested in the steroid hormones and the metabolic disorders.

\section{MODERN TRENDS IN ENDOCRINOLOGY}

Edited by H. Gardiner-Hill, M.D., F.R.C.P. Pp. ix $+298+$ index 13 , illustrated. London: Butterworth \& Co. Ltd. 1958. 65s.

This book is an addition to the 'Modern Trends Series' published by Butterworths. It is a compact account of the subject by British workers, all of whom are active clinical investigators in the subjects which they discuss. It is therefore informative, authoritative and contemporary. It is an excellent book.

\section{ANTISERA, TOXOIDS, VACCINES AND TUBERCULINS IN PROPHYLAXIS AND TREATMENT}

By H. J. PARISH, M.D., F.R.C.P.E., D.P.H. Fourth Edition. Pp. $x+256$, illustrated. Edinburgh: E. \& S. Livingstone Ltd. 1958. 30 .

This book was first published only ten years ago, but has already reached the fourth edition. This in itself is evidence of its popularity and of the rapid expansion of the subject.

The space now given to the Dick test and active immunization against scarlet fever has been reduced following the success of chemotherapy and chemoprophylaxis in the group of diseases caused by haemolytic streptococci. The relatively increased importance of the virus diseases justifies the expansion of this section from two chapters to five; the advances in the prophylaxis of anterior poliomyelitis alone would justify the change in emphasis.

Although the production and standardization of the various preparations are described and there is some discussion of the theory of immunity, the main value of the book will remain the detailed practical instructions that it gives. The author has drawn on his own experience and that of worts associated with him for a generation. Their cômbined knowledge will provide exactly the information needed by the house officer or general prastititioner who finds himself left to decide in isolation on the merits and possibilities of some course- of prophylaxis or who wishes to know the safe dos $\overrightarrow{\mathrm{g}} \mathrm{g}$.

Although the author's own preferences Fare clearly stated he is perfectly fair to preparatigns with which he has not been directly associated, 每d anyone following his advice is unlikely to regre A copy of this book should be available in elery hospital and to every general practitioner.

W.H.H.

ENDOCRINE ASPECTS OF BREAST CANGृER

Edited by A. R. Currie, B.Sc., M.B., F.R.C.P

Pp. xvi +340 , illustrated. Edinburgh: E. $\dot{\alpha}_{\Delta} \mathrm{S}$.

Livingstone Ltd. I 958.37 s. 6 d.

In this book are collected the $5 \mathrm{I}$ short papers read at a three-day conference on the endoctine aspects of breast cancer held in Glasgow in July 1957. The papers are divided into four groư dealing respectively with clinical observations, pathology, hormone studies and experimental pathology, and there is a good index.

The conference was attended by workers in $\frac{5}{\text { this }}$ field from several European countries and frogi to United States, and the whole subject has कुogen covered extremely thoroughly.

\section{MODERN TREATMENT YEARBOOK, $195 \frac{2}{8}$}

Edited by Sir Cecil Wakeley, Bt., M.Ch., D. Fc., F.R.C.S. Pp. viii + 312. Illustrated. Lgndon: Baillière, Tindall \& Cox Ltd. : 958 . 27s. 6d.

This book will interest all, for the contributions cover a wide field, and the high standard of previous editions is maintained. There are interes chapters on the management of congenital heart disease, chronic bronchitis, status asthmaticus înd dyspnoea, the last with a concise review of palmonary physiology.

Helpful accounts are given of the difficulties met with in aged patients, backache and sciatica, complications of head injury, psychogenic syriptoms and the treatment of acute nephritis. Tht are some excellent chapters on gynaecological and obstetric subjects, including the female climacteffic, disorders in adolescence, the modern management of disproportion and ante-natal care.

The reader will also enjoy sections on the case and abuse of eardrops, endocrines in dermatology, the thyroid and radioactive iodine, diarrhoea and steatorrhoea, to mention but a few. It can toe strongly recommended, particularly to the gental practitioner who is looking for practical and lugid accounts of the latest advances in treatment. 